\title{
AGUSTÍN DE ROJAS Y EL QUIJOTE APÓCRIFO
}

\author{
Alejandro Gómez Camacho
}

\begin{abstract}
Él [Cervantes] tomó por tales [medios] ofender a mí y particularmente a quien tan justamente celebran las naciones más extranjeras, y la nuestra debe tanto, por haber entretenido honestísima y fecundamente tantos años los teatros de España ${ }^{1}$.
\end{abstract}

Esta acusación, sin duda cierta, que Alonso Fernández de Avellaneda dirigía contra Cervantes en el prólogo a su Quijote apócrifo es el inicio obligado de cualquier reflexión sobre la personalidad del autor oculto bajo aquel seudónimo. En primer lugar demuestra que la sátira contenida en el prólogo cervantino al Quijote de 1605 no es tan sutil como al lector actual se le antoja. El ingenio de Avellaneda no era demasiado agudo —el prólogo a su libro así lo indica-, luego debemos suponer que los ataques de Cervantes eran fácilmente comprendidos por cualquier lector que conociese la actualidad literaria de los últimos años del Quinientos y el primer lustro del siglo XVI. En segundo lugar Fernández de Avellaneda afirma rotundamente que las burlas de Cervantes se ceban en dos autores: uno sin duda es Lope, y el otro el propio Avellaneda. Hemos de admitir entonces que en el análisis de las alusiones personales contenidas en el prólogo de 1605 se encuentra la clave de la identidad del autor del Quijote de 1614. Este es el camino que me propongo recorrer.

Las referencias a Lope son abundantes, y ya han sido señaladas en numerosos estudios. Sin embargo, ni A. Castro ${ }^{2}$ ni Avalle-Arce ${ }^{3}$ reparan en la que podría ser la primera burla contra el Fénix en el prólogo de 1605; escribe Cervantes:

1 FERnÁNDEZ DE AVELlANEDA, Alonso, Segundo tomo de Don Quijote de la Mancha. Madrid, Castalia, 1972, pág. 52.

2 CAStro, A., «Los prólogos al Quijote», Revista de Filología Hispánica. III, no. 4, págs. 313-338.

3 Cfr. Quijote. Edición y notas de J. B. Avalle-Arce. Madrid, Alhambra, 1979. 
¿ (...), como veo están otros libros, aunque sean fabulosos y profanos, tan llenos de sentencias de Aristóteles, de Platón, y de toda la caterva de filósofos, que admiran a los creyentes y tienen a sus autores por hombres leídos, eruditos y elocuentes? ¡Pues qué cuando citan la Divina Escritura! No dirán sino que son unos santos tomases y otros doctores de la iglesia ${ }^{4}$.

Comparemos ahora con el prólogo a El peregrino en su patria, aparecido en Madrid un año antes que el Quijote:

La esperanza del premio, dice Séneca, que es el consuelo del trabajo. ¿Quién hay en que le espere en este tiempo?, ¿o quién escribe?, si como dice Aristóteles: Delectatio perficit operationem (...). Pues Platón dijo que no debe el verdadero juez, quae determinanda indicio sunt, ab alio discere, (...), pues Dios dijo en el Éxodo: Advenam non contristabis, neque affliges eum: advenae enim et peregrini fuistis in terra Aegipti ${ }^{5}$.

A lo largo de su prólogo Lope cita una vez a Séneca, cuatro a Aristóteles, una a Catón y otra a Demóstenes, Horacio y Salustio. Se cita por último a la Biblia en una ocasión. Parece evidente que Cervantes se refiere al prólogo de Lope, conservando incluso el orden original: Aristóteles, Platón, caterva de filósofos y culminación con las Sagradas Escrituras. Esta comparación de textos da pie para suponer que al redactar su prólogo Cervantes dispone de un ejemplar de $E l$ peregrino en su patria recién impreso - recordemos que la aprobación del Quijote es de septiembre de 1604-y lo escarnece sin dejar lugar a una interpretación ambigua por parte del lector. Si tenemos en cuenta que apenas unos meses separan ambos libros, la sátira cobra una dureza ofensiva contra Lope.

Avalle-Arce propone una nueva alusión contra El peregrino en su patria cuando Cervantes escribe: «y luego en el margen citar a Horacio, o a quien lo dijo» ${ }^{6}$. A pesar de que esta interpretación me sería muy útil en mi análisis, prefiero admitirla con reservas porque no me parece lógico que, tras una referencia textual a la obra de Lope, se incluya una burla tan sutil que apenas se descubre. Por otra parte este mismo texto es uno de los que propone A. Vilanova ${ }^{7}$ como directamente inspirados en el Encomium Moriae, y es poco probable que Cervantes pensase en una obra concreta de Lope cuando adapta un texto de Erasmo. Al autor de El peregrino en su patria le alcanza la sátira como un ejemplo de la falsa erudición sobre la que ironizan Cervantes y su fuente.

El propio Avalle-Arce indica otra alusión textual a La Arcadia de Lope en el prólogo cervantino ${ }^{8}$, e interpreta como una burla a El peregrino en su patria el siguiente pasaje: «(...) de quien nunca se acordó Aristóteles, ni dijo nada San Basilio, ni alcanzó Cicerón» ${ }^{9}$. Los tres autores se citan en el libro de Lope, lo que por proximidad temporal justifica esta interpretación.

4 Ibíd., t., I, pág. 57.

5 VEGA, Lope de, El peregrino de su patria, Madrid, Sancha, 1776, paǵs. XVI-XXVI.

6 Quijote, ed. cit., t. I, pág. 59.

7 Cfr. VILANOVA, A., «La Moria de Erasmo y el prólogo del Quijote», en Collected Studies in Honour of Américo Castro's Eighted year. Oxford, 1965, págs. 422-433.

8 Cfr. Quijote, ed. cit., t. I, pág. 60. n. 17.

9 Ibíd., pág. 62, n. 28. 
Recapitulemos ahora. Encontramos dos parodias textuales de obras de Lope en el prólogo al Quijote de 1605, una referida a El peregrino en su patria, y AvalleArce señala además otras dos puyas dirigidas contra la primera obra, si bien con un carácter más genérico. Llegados a este punto no podemos evitar preguntarnos si existen otras alusiones personales en el prólogo cervantino, y si son suficientes como para que alguien pueda sentirse ofendido en el mismo grado que Lope.

Avalle-Arce entiende una posible crítica a Mateo Alemán en: «ni tiene para qué predicar a ninguno, mezclando lo humano con lo divino» ${ }^{10}$, en el mismo sentido que ya indicó Américo Castro: «esta censura conviene adecuadamente al Guzmán de Alfarache» ${ }^{11}$. En mi opinión la sátira alcanza indirectamente a Alemán, y con igual justificación se podría referir a la Celestina, de la que se dice en los preliminares al Quijote de 1605: «Según siente Celestí-/ libro, en mi opinión diví-/ si encubriera más lo humá-» ${ }^{12}$. El orgullo herido del autor del Quijote apócrifo no puede responder a ofensas tan leves. Si existen las burlas explícitas contra Mateo Alemán, y desde luego el ejemplo anterior no lo es, no son lo suficientemente significativas como para que las tenga en cuenta en este lugar.

Creo sin embargo que existen abundantes alusiones en el prólogo de 1605, en las que no han reparado los estudiosos del tema. Escribe Cervantes en los preliminares de su libro: «ni suplicarte casi con lágrimas en los ojos, como otros hacen, lector carísimo, que perdones o disimules las faltas que en este mi hijo vieres» ${ }^{13}$. La mención directa del pronombre otros me hizo buscar en los prólogos a libros inmediatamente anteriores a 1605 alguno lo suficientemente lacrimoso, que exagerase la humilitas clásica hasta el punto que fuera fácil relacionarlo con este pasaje. En el prólogo a El viaje entretenido de Agustín de Rojas, publicado en Madrid en 1603, muy próximo pues a la aparición del Quijote, se escribe: «no con poco miedo me he atrevido (discretísimo lector) a sacar a la luz esta pequeña obra, siendo como soy en edad tan mozo, en ciencia tan falto y en experiencia tan corto ${ }^{14}$. La proximidad de fechas favorece, como en el caso de Lope, que Cervantes tuviese en cuenta el prólogo de Rojas al redactar el suyo. Entre ambos textos se puede establecer una relación estrecha, favorecida por la proximidad temporal, que posibilita que un lector del Quijote identificase las palabras de Cervantes como una alusión a Rojas, a lo que se suma el hecho de que en los dos casos se intercale un vocativo dirigido al lector acompañado de un adjetivo en grado superlativo.

La segunda referencia a Agustín de Rojas en el prólogo de 1605 se produce por boca del amigo imaginario que aconseja a su autor: «si tratáredes de ladrones, yo os daré la historia de Caco, que me la sé de corrido» ${ }^{15}$. Lo que parece una hipérbole de indudable efecto cómico podría no ser sino una sangrienta burla

10 Ibíd., pág. 62, n. 29.

11 Art. cit., pág. 317.

12 Quijote, ed. cit., t. I, pág. 71.

13 Ibíd., pág. 55 .

14 Ibíd., pág. 60.

15 ROJAS, A. de, El viaje entretenido, Rodríguez Serra, 1901, t. I, pág. 31. 
contra el desdichado Rojas, que apunta en la «Exposición de nombres poéticos que van por declarar en este libro», incluida en El viaje entretenido, la muerte del famoso ladrón Caco a manos de Hércules y Teseo ${ }^{16}$. Es difícil que Rojas no se diese por aludido en las palabras de Cervantes.

Continúa la sátira cervantina en los ejemplos de erudición fácil que el amigo gracioso y bien entendido propone al autor del Quijote. Entre otros, se ridiculizan las anotaciones que tratan sobre Flora, Medea, Circe, Calipso, Alejandro y César, todos los cuales aparecen en la exposición de Rojas. No transcribo todas las anotaciones de estos nombres poéticos por la brevedad obligada en este caso, pero sirvan dos ejemplos:

Flora fue una cantonera que dejó por heredero de su hacienda al pueblo romano, y por esto fue tenida por diosa de las flores, haciéndole las fiestas florarias o laurencias.

Circe, hija del Sol, que con cierta bebida convertía a los hombres en puercos, y así lo hizo con veintidós compañeros de Ulises ${ }^{17}$.

A partir de aquí las alusiones al libro de Rojas se descubren con insistente frecuencia:

ni menos sé qué autores sigo en él, ni para ponerlos al principio, como hacen todos, por las letras de abecé, comenzando por Aristóteles y acabando en Xenofonte y en Zoílo o Zeúxis, aunque fue maldiciente el uno y pintor el otro ${ }^{18}$.

El texto nos remite con bastante precisión a la exposición de Rojas, donde se glosan nombres desde Anfitrite a Zéfiro y Zoroastro, con unos comentarios tan peregrinos que hacen evidente la falsa erudición de Rojas. Insisto una vez más en la proximidad temporal entre los dos libros para justificar que Cervantes se refiriese a Rojas y no a otro, o por lo menos para que el lector del Quijote interpretase así la burla, y no de otra manera.

Propongo como una última alusión a El viaje entretenido la observación que hace Cervantes a su interlocutor imaginario, cuando apunta:

aunque si yo los pidiese a dos o tres oficiales amigos, yo sé que me los darían, y tales que no les igualasen las de aquellos que tienen más nombre en nuestra España ${ }^{19}$.

Baste leer los poemas laudatorios, más de una veintena, que acompañan a la obra de Rojas para suponer por qué había de darse por aludido en esas palabras del prólogo de 1605. Junto a Agustín de Tejada Páez aparecen firmas tan sospechosas como Leandro el cortesano y María de los Ángeles ${ }^{20}$; no es difícil que Rojas notase cierta burla contra su libro.

16 Ibíd., pág. 224.

17 Ibíd., pág. 228 y 232.

18 Quijote, ed. cit., t. I, pág. 57.

19 Ibíd.

20 Del doctor Agustín de Tejada Páez, de Alonso de Contreras, alguacil de la casa y corte del Rey Nuestro Señor, de Don Juan de Piña, de Juana Vázquez, del doctor Francisco de Corcuera a 
No me cabe duda de que la sátira de Cervantes es lo suficientemente sutil como para que sea difícil buscarle un objeto único y exclusivo, sin embargo considero que Agustín de Rojas es burlado con claridad en el prólogo al Quijote. Las alusiones son demasiado frecuentes como para que se las considere meras coincidencias. Admito que puedan alcanzar a más personas o colectivos, pero sin duda aciertan de pleno en Rojas; además la proximidad cronológica entre los dos libros favorece la identificación de El viaje entretenido como el blanco de las burlas.

Pienso que, frente a lo que se ha venido insinuando, los ataques contenidos en el prólogo cervantino no responden, o no solamente a rivalidades personales o estéticas. En su lugar propongo algo mucho más simple; Cervantes se enfrenta en su prólogo a los dos libros de entretenimiento que aparecen inmediatamente antes que el suyo: El peregrino en su patria y El viaje entretenido. De esta manera obtiene un doble resultado al delimitar el espacio literario que habría de ocupar su Quijote, desprestigiando de paso a dos temibles competidores y beneficiándose de la fama que aquellos pudieran tener ya en 1605 . No olvidemos que a priori el Quijote, y probablemente su autor, constituían una absoluta novedad en las letras españolas y podían alcanzar un fracaso igualmente absoluto frente a autores y obras de corte más tradicional.

Si Alonso Fernández de Avellaneda se reconoce como el principal afectado, junto a Lope, por las burlas contenidas en el prólogo al Quijote de 1605, y sí, como espero haber demostrado, Agustín de Rojas es, con Lope, el autor al que más veces se alude en el prólogo cervantino, ¿no es probable que El viaje entretenido y el Quijote apócrifo tengan un mismo autor?

Sería interesante realizar un minucioso análisis comparativo de ambos libros, atendiendo a hábitos morfosintácticos, frecuencia de elementos léxicos característicos, dialectalismos, y en general todo lo que permita suplir la carencia documental que protege celosamente la personalidad del autor del Quijote de 1614.

Sevilla, mayo, 1986.

Agustín de Rojas, de don Luis de Velasco, caballero del hábito de Santiago, de doña Juana de Figueroa, de Alonso de Salas Barbadillo, de doña Antonia de la Paz, de Leonardo el cortesano a A. de Rojas, de María de los Ángeles, del lcdo. Francisco Sánchez de Villanueva, de don Antonio de Rojas, caballero del hábito de Santiago, del lcdo. Francisco de Aranda, de doña María de Guzmán, de Pedro Juan de Ochoa, de Fernando de Ledesma, de Felipe de Sierra al celebrado Rojas, de Luis Vélez de Santander, del lcdo. Juan de Valdés y Meléndez, de doña Inmaculada de Artiaga, de Juan Gerónimo Sierra, criado de su Magestad, de don Alonso de Trujillo, criado del marqués del Carpio. 
